\title{
The role of working memory in childhood education: Five questions and answers
}

\author{
Kate Cockcroft, University of Witwatersrand.*
}

\begin{abstract}
Working memory is the mental ability to temporarily store and manipulate information. Its functioning is distinct from the vast storage capacity of long-term memory and is crucial for optimal learning and development. There is considerable research on several theoretical aspects of working memory. Far less research has explored the application of such theory in order to understand how children perform in educational settings and to support and improve their academic performance. In this paper, five key aspects regarding working memory are considered and their implications for early childhood development, learning and education are discussed. These aspects include the role of the different components of working memory in early childhood learning, ways in which working memory is assessed in children, how verbal and visual working memory develop, how working memory difficulties manifest in children, and ways in which working memory can be improved.
\end{abstract}

Keywords: academic success, cognition, development, learning, working memory

*Email address: kate.cockcroft@wits.ac.za.

South African Journal of Childhood Education | 2015 5(1): 1-18 | ISSN: 2223-7674 |๔ UJ
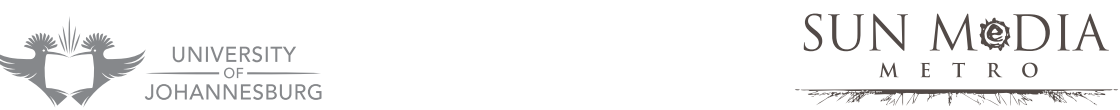


\section{Introduction: Taking a construct from the psychology laboratory and theory to the practice of childhood education}

The process that enables humans to mentally hold small amounts of information in a readily accessible state and to use them in complex cognitive tasks is known as working memory. It interacts closely with long-term memory and enables us to plan, reason, solve problems, read, write and abstract the gist of information (Baddeley \& Hitch 1974; St Clair-Thompson, Stevens, Hunt \& Bolder 2010). It is therefore unsurprising that working memory is one of the most widely researched constructs in education and psychology (Cowan 2014). However, while much research has focused on the theoretical aspects of working memory, far less work has been concerned with how an understanding of working memory can be applied to everyday situations. Translation of laboratory findings to everyday application is often a major challenge, and one needs to be cautious when extrapolating from such tightly controlled research environments to uncontrollable everyday situations. Furthermore, most working memory research has focused predominantly on adult populations, with considerably less attention paid to working memory in children. Understanding how working memory operates and can be enhanced has relevance for all aspects of our lives, and particularly for how children learn, since it is heavily implicated in classroom activities that involve following instructions, focusing and completing tasks (Gathercole \& Alloway 2008; Holmes \& Gathercole 2014). In this article, I pose and answer five questions related to working memory and its application to childhood education, learning and development. In answering these questions, I critically consider the effective translation of current research findings to the school and home learning environments.

\section{Why is working memory so important for childhood learning and education?}

There is considerable evidence linking performance on working memory tasks to vocabulary acquisition (Engel de Abreu, Gathercole 2006; Gathercole \& Martin 2011); early academic success in reading (Gathercole \& Alloway 2008; Stevenson, Bergwerff, Heisera \& Resinga 2014); mathematics (Arndt, Sahr, Opfermann et al 2013; Bull \& Scerif 2001; DeStefano \& LeFevre 2004); and comprehension (Cain, Oakhill \& Bryant 2004; Seigneuric, Ehrlich, Oakhill \& Yuill 2000). Furthermore, measurements of working memory ability taken at the commencement of formal education are much stronger predictors of success in reading, spelling and mathematics than IQ scores (Alloway 2008; Alloway \& Alloway 2010) and short-term memory ability (Engle, Tuholski, Laughlin \& Conway 1999). In order to understand the relationship between working memory and academic performance, it is necessary to first provide some theoretical detail.

Baddeley's (2000; 2003) working memory model is the best known, most researched and most widely accepted theoretical model, although many other equally feasible models exist (for example, Anderson 1983; Cowan 2008; Ericsson \& Kintsch 1995; Miyake \& Shah 1999; Oberauer 2005). These models differ primarily in their conceptualization of the relationship between working memory and long-term 
memory, the nature of the executive control mechanism(s), and the capacity of working memory. They are, however, in general agreement that working memory comprises several components or processes that operate in a coordinated manner in order to temporarily store and manipulate information (Baddeley 2003; Cowan 2008; Ericsson \& Kintsch 1995; Miyake \& Shah 1999; Oberauer 2005). These components include separate verbal and visuospatial subsystems - the phonological loop and the visuospatial sketchpad, respectively - each of which has a limited capacity. The phonological loop consists of a phonological store (for passive storage) and an articulatory rehearsal system (for active rehearsal and maintenance of information). These processes are responsible for integrating auditory information into meaningful sounds, such as phonemes, words and sentences. The visuospatial sketchpad is similarly subdivided into the visual cache (for storage of static visual/spatial information) and the inner scribe (for rehearsal) (Buchsbaum 2013; Logie 1995). These processes are critical for interpreting and integrating information from the visual world around us, which would otherwise constitute a series of disjointed snapshots (Simmering 2012). Evidence suggests that visual and spatial information are separate in working memory, and this is supported by different anatomical brain locations for the storage and processing of visual as opposed to spatial information (Holmes, Adams \& Hamilton 2008).

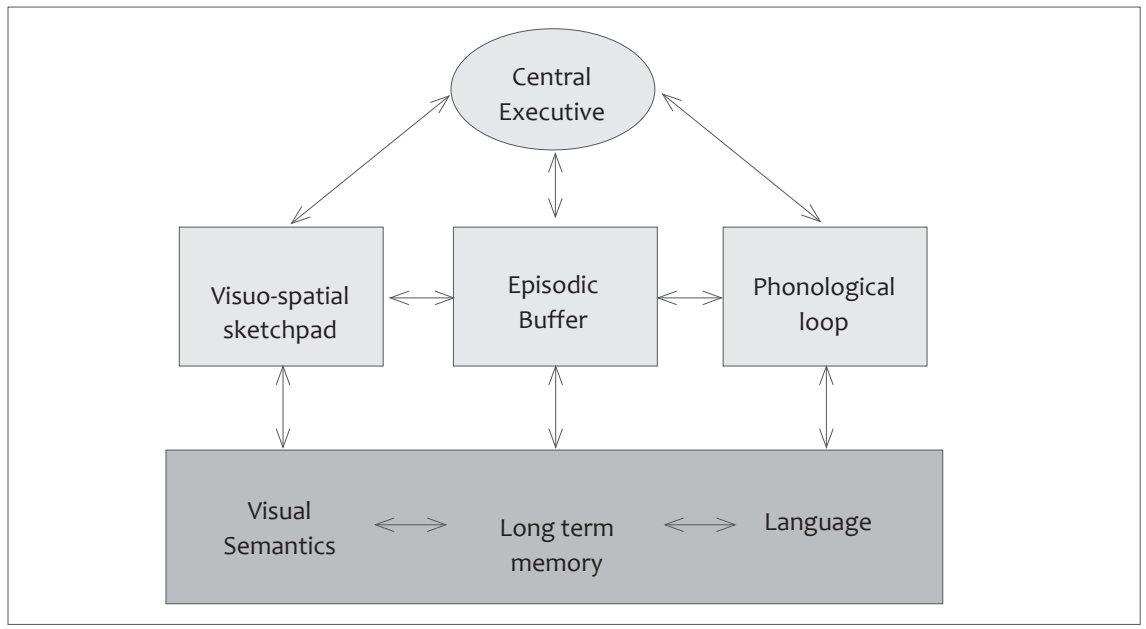

\section{Figure 1. Schematic representation of working memory.}

In addition to the modality specificity of these components (verbal, visual and spatial), a key aspect of this model is the distinction between simple, short-term memory (brief storage only, with no explicit processing) and complex manipulation or processing of information (See Cowan 2008 for a detailed discussion). Neuroimaging studies confirm these distinctions, with simple, storage-only tasks activating brain areas related to the to-be remembered information (for example, Broca's area in the 
case of verbal material, and the right hemisphere premotor cortex for visuospatial material). Combined storage and processing tasks, on the other hand, show both content-specific activation and activation in other areas, such as the dorsolateral prefrontal cortex and anterior cingulate cortex (which reflect the involvement of executive control and attention) (Jonides, Lacey \& Nee 2005).

The verbal and visuospatial storage components of working memory are overseen by a domain-general component, the central executive. This is a shared attentional mechanism that controls encoding into the verbal and visuospatial stores and plays several regulatory roles, which include accessing information from long-term memory, paying attention, planning, inhibiting automatic behaviours, and simultaneously holding and processing information (Heyes, Zokaei, Van der Staaij et al 2012; Kane \& Engle 2003; Pickering 2001).

The fourth component of working memory is the episodic buffer, which holds semantic information for short periods, binds phonological and visuospatial information, and integrates and consolidates information from long-term and immediate memory into coherent episodes (Baddeley 2003). All of these components are critical for effective learning, with different tasks making differential demands on them.

Certain academic tasks draw more on the central executive (for example, solving novel problems, reading comprehension, conceptual development, multistep arithmetical problems), while others may require more involvement from the phonological loop (for example, vocabulary acquisition, reading, arithmetical word problems; Gathercole 2006) or visuospatial sketch pad (learning numbers, interpreting graphs; Heyes et al 2012). Clear links have been demonstrated between the phonological loop and the acquisition of vocabulary in the mother tongue and additional languages (Gathercole 2006; Engel de Abreu et al 2011; Masoura \& Gathercole 2005; Stevenson et al 2014). The ease with which new words are learned is strongly constrained by a child's phonological loop capacity, together with existing language knowledge stored in long-term memory. When the child comes across unfamiliar phonological forms for which no such stored knowledge is available to support learning, she must of necessity rely completely on the fragile phonological loop system to provide the necessary temporary storage of the phonological material while more stable and enduring longterm phonological representations are being formed. The phonological loop mechanism linking phonological memory and vocabulary acquisition is the phonological store. Evidence indicates that the phonological store is in place as soon as the child begins to develop language, while subvocal rehearsal as a means of silently preserving the contents of the phonological store only emerges around the age of seven years (Baddely, Gathercole \& Papagno 1998).

The phonological loop and visuospatial sketchpad are both implicated in counting and mental arithmetic (Stevenson et al 2014; Trbovich \& LeFevre 2003), while different aspects of the visuospatial sketchpad are implicated in mathematics calculations at different ages (Holmes et al 2008). There appears to be a greater reliance on the spatial component in younger children (seven- to eight-year-olds), while older children (nine-to ten-year-olds) rely more on the visual component. It is proposed that 
younger children need to form a spatial image on a mental blackboard while solving mathematical problems, while older children, who have more strategies (including verbal ones) available to them, rely less on such mental models of problems; instead, they appear only to rely on storage of the problem information in the visual cache (Holmes et al 2008).

Reliance on working memory during learning is a feature of early childhood, when the young child does not have many learned automatized skills (such as alphabetic and numerical knowledge). While the precise mechanisms that underlie the relationships between working memory and academic ability are not fully understood, evidence indicates that limits in working memory constrain learning (Cowan 2014).

Although working memory performance is a stronger predictor of academic success than IQ scores, working memory is not a substitute for IQ, as it represents a separate cognitive ability from IQ, with separate and distinctive links to academic success (Alloway 2008; Alloway \& Alloway 2013; Little, Lewandowsky \& Craig 2014). These links are believed to arise from the close relationship between working memory and fluid intelligence, which reflects reasoning and processing speed, as well as the ability to solve novel problems. IQ scores, on the other hand, correspond more closely to crystallized intelligence, which reflects acquired knowledge obtained from one's experiences, culture and education (Little et al 2014; Wilhelm \& Engle 2005). Although distinct constructs, fluid and crystallised ability are related. Cowan (2014) suggests that a good working memory assists with problem solving (hence the relationship with fluid intelligence) and that fluid intelligence and working memory together assist with new learning (hence the relationship with crystallised intelligence). IQ and working memory are partly related, as they share effective use of the simple, short-term storage component of working memory (Colom, Abad, Quiroga et al 2008). Consequently, both are constrained by the capacity limits of short-term storage (that is, the amount of information that can be temporarily stored in a consistent state), which would influence how effectively a child can store crystallised knowledge. However, working memory appears to have a stronger relationship with fluid intelligence, which forms only a small component of the skills tested in traditional IQ tests (Engel de Abreu, Conway \& Gathercole 2010). Thus, working memory assessments could be a valuable supplement to traditional knowledge-based assessments in early childhood to identify children who are at risk of experiencing academic difficulties.

\section{How is working memory assessed?}

Working memory capacity is typically evaluated with span-type tasks in which the participant must engage in immediate processing while retaining information for either instant or later recall. In these tasks, the span (capacity) of working memory is determined for different modalities (verbal, visual or spatial) and under different conditions (for example, performing a visual span task while simultaneously inhibiting attention to irrelevant verbal information). In listening span tasks (measuring the central executive and phonological loop), the participant must make judgments 
about the meaning of each of a series of between four and six sentences and then attempt to recall the final word in each sentence (Daneman \& Carpenter 1980); in digit span backwards tasks (measuring the central executive and phonological loop), the participant must reorder a series of orally presented digits from last to first; in backwards spatial span tasks (measuring the central executive and visuospatial sketchpad), the participant must recall a set of blocks that have been tapped in reverse sequence (Alloway 2007; Wechsler 2009). These complex span tasks can be distinguished from those that measure simple, short-term memory span, which require immediate recall of information with no additional processing as, for example, in digit span tasks, where the participant must listen to and immediately recall a series of digits (phonological loop), or block recall, where the participant must recall the sequence of a set of blocks which have been tapped by the tester (visuospatial sketchpad) (Pickering \& Gathercole 2001). Higher scores on simple span tasks indicate greater short-term memory capacity, while higher scores on complex span tasks indicate greater working memory or executive control (Hornung, Brunner, Reuter \& Martin 2011). Although short-term storage and working memory processing are theoretically distinct constructs, they are very closely related and are evaluated based on the extent to which a task would predominantly implicate storage or processing (Conway, Jarrold, Kane et al 2008).

Since the procedures and stimuli used in working memory tests are designed to be equally unfamiliar (for example, nonsense words or shapes) to all participants, they are unlikely to confer any obvious advantages or disadvantages on children with differing prior knowledge and experience (Engel, Dos Santos \& Gathercole 2008). For this reason, working memory ability appears to be relatively unaffected by environmental factors such as the quality of social and intellectual input in the home environment, rural or urban living conditions, socio-economic status (SES), or preschool attendance (Alloway, Gathercole, Willis \& Adams 2004; Engel et al 2008; Rinderman, FloresMendoza \& Mansur-Alves 2010). The fact that income and parental level of education appear not to influence working memory ability suggests that working memory could be a useful measure of all children's learning potential, irrespective of background. This is because working memory (through its association with fluid intelligence) provides an indication of a child's ability to learn, rather than what she has already learned.

Working memory span is not constant. Instead, there are developmental differences in terms of the average working memory span at different ages across childhood.

\section{How does working memory develop?}

Like other cognitive capacities, working memory capabilities change over an individual's lifespan (Bauer \& Fivush 2013; Gathercole, Pickering, Ambridge \& Wearing 2004). This is most noticeable in terms of the number of items or chunks that can be held in working memory, which increases steadily with maturation and reaches a peak around the age of sixteen years, a finding which is consistent across many cultures (Alloway et al 2004). The working memory capacity that a person has in late adolescence is likely to remain 
constant until approximately forty-five years of age, when it starts to decline (Alloway 2011; Cowan 2010; Simmering \& Perone 2013).

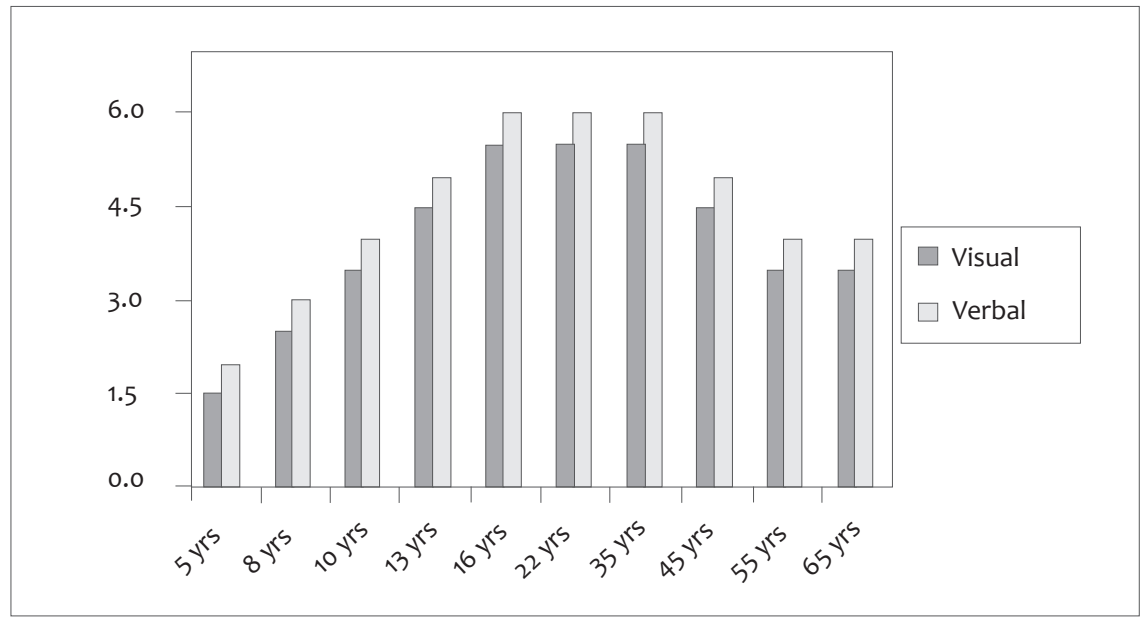

Figure 2: The development of working memory capacity (Adapted from Alloway 2011)

(Note: The y-axis represents the number of chunks recalled.)

The $y$-axis of Figure 1 shows the number of verbal (spotted bar) and visual (solid bar) items that the average individual can retain in working memory at different ages. These limits to working memory at each age have implications for teaching; for example, the average eight-year-old would find it difficult to recall more than three verbal items or instructions in class. While a typical adult can hold between five and nine verbal items in working memory, fewer visual items can be retained (between three and four; Baddeley 2000; Heyes et al 2012).

Since the number of items depicted on the y-axis of Figure 1 represents averages; there will always be some individual variation within each age group. Exceptions to this typical developmental trajectory could occur in cases where the child develops an interest (such as chess or a computer game) that places heavy demands on working memory and provides greater than average opportunities for its development. Consequently, variations in working memory capacity, as well as the increase in ability over maturation, are believed to arise from a combination of individual differences in strategy use (for example, rehearsal, organization/chunking, imagery, etcetera) and physiological factors, such as increased myelination of neurons in the brain, which in turn increases the speed and efficiency of information processing (Case 1995; Conway et al 2008). Faster rates of information processing reduce the effects of decay and interference in working memory and allow for faster retrieval of information from longterm memory (Cowan, Wood, Wood et al 1998). Thus, as processing efficiency improves during development, resources are freed up for other mental operations, and this is reflected in improved working memory performance with age (Conway et al 2008). In 
addition, the developing child's increasing long-term memory knowledge base provides a framework for better storage and retrieval of verbal and visuospatial information. This is accompanied by increasing attention abilities, which, together with the expanding knowledge base, allow for improvements in the use of memory strategies (ibid).

Thus, there are developmental increases in both working memory storage capacity and processing ability, with the former developing from an earlier age. Rehearsal strategies - such as repeating words mentally or out aloud, visual imagery or chunking - only become evident from approximately seven years of age and then increase in complexity (Gathercole 1998). Prior to formal schooling, there tends to be a reliance on spontaneous visual encoding or storage mechanisms. Formal schooling, the acquisition of literacy and the development of the frontal lobes (which are largely responsible for executive control) introduce more verbal encoding, and from the middle primary years children are able to consciously choose between using increasingly more sophisticated visuospatial or phonological mechanisms to rehearse new information (Cowan 2014; Palmer 2000; Pickering 2001). More sophisticated organisational memory strategies, such as chunking and visual imagery, which reduce the number of items to be retained in memory by forming associations that combine the information into larger units, emerge from middle childhood (around nine years of age) (Cowan 2014; Garcia, Nussbaum \& Preiss 2011; Kyndt, Cascallar \& Dochy 2012). Visual objects may often be encoded with verbal labels in older children and adults, and may be rehearsed using phonological methods (Pickering 2001). Given this developmental trajectory, greater reliance should be placed on visual learning methods in the foundation school years, with progressively greater dependence on verbal learning from middle primary onwards.

Thus, unlike long-term memory, working memory's storage capacity is very limited (between one and a half and six chunks of information, depending on the modality and age of the child) (Baddeley 2003; Cowan 2001; Oberauer 2005). These limits on working memory place constraints on a range of cognitive tasks, so that individuals with greater spans typically perform better than individuals with lesser capacity.

\section{How do working memory difficulties in manifest in children?}

When faced with challenging cognitive tasks, children with low memory spans tend to 'zone out' or mentally wander from the task. Consequently, working memory problems are often identified as attention problems (Alloway 2008; Kane, Brown, McVay et al 2007). This is not an inaccurate assessment of the difficulties experienced by these children. Difficulty in maintaining attention is a typical feature of an overloaded working memory that cannot retain the information needed to complete an ongoing mental activity. As a result, these children often fail to follow instructions or abandon tasks quickly. In addition, children with poor working memories struggle particularly with tasks that have many simultaneous processing demands, such as remembering multipart instructions and keeping track in multilevel tasks such as listening and writing (Gathercole, Lamont \& Alloway 2006). Consequently, children with working memory difficulties may permanently 'lose' information that forms a vital foundation 
for the acquisition of knowledge and skills in important academic areas such as language studies, mathematics and science (Alloway 2006, 2009; Baddeley 2003; Gathercole \& Pickering 2000; 2003). They may also experience difficulty updating or refreshing information in memory if they cannot properly retrieve information from long-term memory to support that which is being held in working memory. This would lead to difficulty in selecting and integrating relevant information in a particular academic subject. Even if a task contains only small amounts of irrelevant information, children with working memory difficulties may have difficulty inhibiting or blocking out this competing information, resulting in working memory overload (Alloway 2006). Finally, these children may battle when they need to mentally shift between concepts and information, for example in mathematics, when they have to perform multi-digit operations that require shifting between mathematical procedures (Pickering 2006).

Children with limited working memory capabilities can be assisted through deliberate management of working memory loads in the classroom. In order to achieve this, the demands made on working memory by various classroom activities should first be determined. Activities may either be storage- or storage- and processing-dependent. The first type entails the storage of substantial amounts of arbitrary information, such as the precise wording of a long sentence; the second involves storage and simultaneous mental engagement in a demanding activity, such as performing a mathematical calculation or a reading comprehension task (Alloway 2006; Pickering 2006). Once the demands made on working memory by a particular classroom task have been determined, its component parts should be reduced and simplified into smaller components. This could involve writing them in different coloured inks or chalks (providing a visual cue for the child), or numbering written lines of text to help the child keep her place.

Children with poorer working memories find timed tasks difficult and generally need more time to process information. For these children, instructions should be repeated frequently and at a slower pace, and the child should be encouraged to repeat instructions back. In order to avoid overtaxing a young child's working memory, the teacher should present only one or two items or ideas simultaneously and avoid giving unintegrated material to retain for long periods. It is important to consider the working memory demands of verbal instruction, as they may not always match the child's language comprehension abilities. It also useful to monitor the child's working memory regularly during the execution of demanding activities and to get her to articulate what she found difficult about the task. Usually the difficulties translate to problems with either storage or processing. This information should enable the educator to provide appropriate feedback on how to address these difficulties (Alloway \& Gathercole 2006; Gathercole \& Alloway 2004; 2008).

Working memory impairments are six times more likely to occur in children with special educational needs than in typically developing children (Pickering \& Gathercole 2001). Some of the neurodevelopmental disorders that are accompanied by working memory difficulties include attention-deficit/hyperactivity disorder (ADHD), autistic spectrum disorders (ASD), developmental coordination disorder, schizophrenia, 
prematurity, dyslexia, dyscalculia, dyspraxia, foetal alcohol spectrum disorders, specific language impairment, fragile $X$ syndrome (FXS), Down syndrome and Williams syndrome (Alloway, Gathercole, Kirkwood \& Elliott 2009; Pickering 2006; Rajendran 2009; Sabol \& Pianta 2012). Although these disorders differ considerably from each other, children with these disorders all find it difficult to acquire key academic skills and concepts, and could benefit immensely from the effective management of working memory demands in the classroom.

Children with working memory difficulties are relatively common in every classroom and are at risk of poor academic progress if their working memory difficulties are not addressed (Alloway et al 2009; Sabol \& Pianta 2012). Recently there has been considerable interest in working memory intervention programmes.

\section{Can working memory capacity be improved?}

Without early intervention, working memory difficulties will not spontaneously correct as a child develops and will impede a child's likelihood of academic success (Alloway 2011). However, there is evidence that working memory functioning can be altered (Henry, Messer \& Nash 2014; Holmes \& Gathercole 2014; Klingberg, Fernell, Olesen et al 2005; Klingberg, Forssberg \& Westerberg 2002; Minear \& Shah 2006). Functional magnetic resonance imaging ( $\mathrm{fMRI}$ ) studies following working memory training have shown an increase in brain activity in the prefrontal (executive control) and parietal (visuospatial functioning) areas of the brain, as well as changes in dopamine receptor density (implicated in focused attention) (Curtis \& D'Esposito 2003; Klingberg 2010; Klingberg et al 2002). This suggests that there is plasticity in the neural networks involved in working memory. Furthermore, these changes appear in the multimodal association cortices, which are parts of the brain that are not tied to any specific sensory modality but are involved in a wide range of cognitive activities that tap working memory (Olesen, Westerberg \& Klingberg 2004).

Much of the training to improve working memory focuses on developing the executive control processes to effectively use strategies that will enhance working memory's limited capacity and to prevent interference and decay (Cowan 2008). The training may involve either explicit teaching of memory strategies or implicit training through the completion of appealing visuospatial and/or verbal tasks that place demands on working memory. The latter tasks are typically computerized in nature and involve repeated trials with rewards and feedback based on the accuracy of responses, but can also be presented in paper and pencil format. Improvements in working memory following training have been reported in typically developing preschool and primary school children (Henry et al 2014; Thorell, Lindqvist, Bergman et al 2009); children with ADHD (Beck, Hanson, Puffenberger et al 2010; Holmes, Gathercole, Place et al 2010; Klingberg et al 2005); and children with cochlear implants (Kronenberger, Pisoni, Henning et al 2011). In children with poor working memories such training improves memory performance to the extent that it reaches typical levels of functioning for most, and these gains persist six months after the training 
has finished (Holmes et al 2010; Kerns, Eso \& Thomson 1999; Klingberg et al 2005). There is also evidence of improved learning in other academic areas following working memory training, with significant improvements in reading comprehension (Dahlin 2010) and in mathematics test scores found several months after training (Holmes, Gathercole \& Dunning 2009). Such improvements may be mediated or enhanced by positive feedback, since an initial improvement in working memory may subsequently lead to increased participation in mentally demanding activities, which in turn sustains the training effects (Klingberg 2010). However, these effects should be interpreted with caution, as they have as yet only been demonstrated under carefully controlled research conditions, where the training is implemented by experienced researchers under optimal and resource-intensive conditions that are very different to the everyday circumstances in which such programmes will be used (Holmes \& Gathercole 2014).

While there is considerable evidence that working memory can be trained, research on the transfer of these skills to other areas of functioning is equivocal (Henry et al 2014; Holmes et al 2009; Morrison \& Chein 2012). Some studies suggest that working memory training improves performance on the trained tasks, but does not generalize to reasoning tasks that rely on working memory (Melby-Lervag \& Hulme 2013). The effects of working memory training on a particular brain region could only be expected to transfer to other functions and tasks if the untrained tasks utilise the same neural systems (Olesen et al 2004). In this regard, the positive effects resulting from working memory training have been found to transfer to related tasks, such as tasks that require following instructions, nonverbal reasoning and mathematical problem solving, and tasks that involve attentional control (Brehmer, Westerberg \& Backmann 2012; Holmes et al 2009; Jaeggi, Buschkuehl, Jonides \& Perrig 2008). Thus, working memory training could be an effective intervention for children whose low working memory capacity has a deleterious effect on their academic performance and/or everyday life. If used in conjunction with classroom management techniques to minimize working memory demands, the training could produce noticeable benefits for such children.

A few general principles can be identified from the research on working memory training and generalized to the classroom situation, should an educator wish to use working memory tasks in this context. Firstly, tasks used to train working memory should be varied. The skills acquisition literature indicates that variability in training fosters greater flexibility and likelihood of transfer (Schmidt \& Bjork 1992). Secondly, the duration of training is important. Effective programmes are time-intensive, comprising 30-40 minutes per day, five days a week, for at least five weeks (Shipstead, Hicks \& Engle 2012). Consequently, there needs to be substantial commitment and monitoring of compliance to the programme by a teacher, parent, or other responsible person. Thirdly, the difficulty level of the training tasks need to be regularly adapted. Pitching tasks at a level that is far beyond the child's capabilities will demotivate her and discourage participation. Similarly, maintaining tasks at a level that does not challenge the child is unlikely to result in any working memory gains. In support of this, Klingberg et al (2002) compared a control group and intervention group, both 
of whom received the same working memory training, but with the difference that the control group was exposed to the training for a shorter period and with no adaptations for difficulty level. The intervention group improved significantly, while the control group did not.

The more explicit way of improving working memory involves the teaching of "mentally effortful, goal-directed processes that are adopted to enhance memory performance”, or memory strategies (St Clair-Thompson et al 2010:205). Very few preschool and early foundation level children spontaneously use memory strategies. This does not mean that such young children cannot be trained in the use of strategies (Bjorkland \& Douglas 1997). Strategies that involve organising material are the least likely to be used spontaneously by young children and should thus be taught in order to help reduce memory load. Related techniques include using visual and verbal images (which helps to organize the material and associate ideas to one another to form bigger chunks and form a coherent framework, thereby reducing the working memory load and creating links with long-term memory), and (for slightly older children) reading ahead to prepare for the next day's work (which strengthens the memory trace and creates an organisational framework for new material) (Bjorkland \& Douglas 1997; Ericsson \& Kintsch 1995).

Thus, working memory can be assisted and improved in a number of ways, namely by effectively managing the demands made on it by classroom activities, by providing training in demanding tasks that implicitly strengthen working memory, or by explicitly teaching the child effective memory strategies. Given the theoretical links between working memory and children's learning and educational performance, it follows that improvements in working memory have the potential to improve scholastic functioning. The potential economic and educational benefits of early intervention using working memory training are valuable and should be explored.

\section{Conclusion: Targeted interventions and strategic classroom management}

A child may try really hard at school but still struggle to learn. In such cases, often "the problem isn't effort; the problem is working memory" (Alloway 2011:9). Limitations in working memory capacity negatively impact cognition, development and learning in both typical and atypical child populations, as they may impair a child's ability to extract information and learn the skills that form the basis for later effective functioning in mathematics, science, language studies and interpersonal interactions (Cowan 2014). In this paper, I have taken the available empirical research on working memory functioning in children to the level of practical application and relevance for early childhood learning and education. I conclude on the positive note that working memory difficulties can be addressed through targeted interventions, effective classroom management of working memory load, and the teaching of specific strategies. However, since the research on which these applications are based was conducted in laboratory-style settings removed from the less controllable everyday world, it is important to start exploring how effectively they may generalize to such a world. 


\section{References}

Alloway, T.P. \& Alloway, R.G. 2010. Investigating the predictive roles of working memory and IQ in academic attainment. Journal of Experimental Child Psychology, 106(1):20-29.

Alloway, T.P. \& Alloway, R.G. 2013. The new IQ: Using your working memory to think stronger, smarter, faster. London: Fourth Estate.

Alloway, T.P. \& Gathercole, S.E. 2006. How does working memory work in the classroom? Educational Research and Review, 1(1):134-139.

Alloway, T.P. 2006. How does working memory work in the classroom? Educational Research and Reviews, 1(4):134-139.

Alloway, T.P. 2007. Automated Working Memory Assessment. London: Pearson Assessment.

Alloway, T.P. 2008. Working memory: The new IQ? PATOSS, 21:9-10.

Alloway, T.P. 2009. Working memory, but not IQ, predicts subsequent learning in children with learning difficulties. European Journal of Psychological Assessment, 25(2):1-7.

Alloway, T.P. 2011. Improving working memory: Supporting students' learning. London: Sage.

Alloway, T.P., Gathercole, S.E., Kirkwood, H. \& Elliott, J. 2009. Evaluating the validity of the Automated Working Memory Assessment. Educational Psychology, 28(7):725- 734.

Alloway, T.P., Gathercole, S.E., Willis, C. \& Adams, A.M. 2004. A structural analysis of working memory and related cognitive skills in early childhood. Journal of Experimental Child Psychology 87(2):85-106.

Anderson, J.R. 1983. The Architecture of Cognition. Cambridge, MA: Harvard University Press.

Arndt, D., Sahr, K., Opferman, M., Leutner, D. \& Fritz, A. 2013. Core knowledge and working memory as prerequisites of early school mathematics. South African Journal of Childhood Education, 3(1):1-20.

Baddeley, A.D. 2000. The episodic buffer: A new component of working memory? Trends in Cognitive Sciences, 4(11):417-423.

Baddeley, A.D. 2003. Working memory and language: An overview. Journal of Communication Disorders, 36(3):189-208.

Baddely, A.D. \& Hitch, G.J. 1974. Working memory. In: G.H. Bower (Ed). The Psychology of Learning and Motivation. Volume 8. New York: Academic Press. 47-90.

Baddely, A.D., Gathercole, S.E. \& Papagno, C. 1998. The phonological loop as a language learning device. Psychological Review, 105(1):158-178.

Bauer, P.J. \& Fivush, R. 2013. Handbook on the development of children's memory. New York: Wiley.

Beck, S.J., Hanson, C.A., Puffenberger, S.S., Benninger, K.L. \& Benninger, W.B. 2010. A controlled trial of working memory training for children and adolescents with ADHD. Journal of Clinical Child and Adolescent Psychology, 39(6):825-836. 
Bjorkland, D.F. \& Douglas, R.N. 1997. The development of memory strategies. In: N. Cowan \& C. Hulme (Eds). The development of memory in childhood. Sussex: Psychology Press. 201-246.

Brehmer, Y., Westerberg, H. \& Backmann, L. 2012. Working memory training in younger and older adults: training gains, transfer and maintenance. Frontiers in Human Neuroscience, 6(63):1-7.

Buchsbaum, R. 2013. The role of consciousness in the phonological loop: hidden in plain sight. Frontiers in Psychology, 4:1-5.

Bull, R. \& Scerif, G. 2001. Executive functioning as a predictor of children's mathematical ability: inhibition, switching and working memory. Developmental Neuropsychology, 19:273-293.

Cain, K., Oakhill, J. \& Bryant, P. 2004. Children's reading comprehension ability: Concurrent prediction by working memory, verbal ability, and component skills. Journal of Educational Psychology, 96(1):31-42.

Case, R. 1995. Capacity-based explanations of working memory growth: a brief history and a re-evaluation. In: F.M. Weinert \& W. Schneider (Eds). Memory Performance and Competencies: Issues in Growth and Development. Mahwah, NJ: Erlbaum. 23-44.

Colom, R., Abad, F.J., Quiroga, M.A., Shih, P.C. \& Flores-Mendoza, C. 2008. Working memory and intelligence are highly related constructs, but why? Intelligence, 36(6):584-606.

Conway, A.R.A., Jarrold, C., Kane, M., Miyake, A. \& Towse, J. 2008. Variation in Working Memory. New York: Oxford University Press.

Cowan, N. 2001. The magical number 4 in short-term memory: a reconsideration of mental storage capacity. Behavioural and Brain Sciences, 24(1):87-185.

Cowan, N. 2008. What are the differences between long-term, short-term and working memory? In: W.S. Sossin, J.C. Lacaille, V.F. Castellucci \& S. Belleville (Eds). Progress in Brain Research. Amsterdam: Elsevier. 323-338.

Cowan, N. 2010. The magic mystery four: how is working memory capacity limited and why? Current Directions in Psychological Science, 19:51-57.

Cowan, N. 2014. Working memory underpins cognitive development, learning and education. Educational Psychology Review, 26(2):197-223.

Cowan, N., Wood, N.L., Wood, P.K., Keller, T.A., Nugent, L.D. \& Keller, C.V. 1998. Two separate verbal processing rates contributing to short-term memory span. Journal of Experimental Psychology: General, 127(2):141-160.

Curtis, C.E. \& D'Esposito, M. 2003. Persistent activity in the prefrontal cortex during working memory. Trends in Cognitive Science, 7(9):415-423.

Dahlin, K. 2010. Effects of working memory training in children with special needs. Reading and Writing, 24(4):479-491.

Daneman, M. \& Carpenter, P.A. 1980. Individual differences in working memory and reading. Journal of Verbal Learning and Verbal Behaviour, 19(4):450-466. 
DeStefano, D. \& LeFevre, J. 2004. The role of working memory in mental arithmetic. European Journal of Cognitive Psychology, 16:353-386.

Engel de Abreu, P.M.J, Gathercole, S.E. \& Martin, R. 2011. Disentangling the relationship between working memory and language: The roles of short-term storage and cognitive control. Learning and Individual Differences, 21(5):569-574.

Engel de Abreu, P.M.J., Conway, A.R.A. \& Gathercole, S.E. 2010. Working memory and fluid intelligence in young children. Intelligence, 38(5):552-561.

Engel, P.M.J., Dos Santos, F.H. \& Gathercole, S.E. 2008. Are working memory measures free of socio-economic influence? Journal of Speech, Language and Hearing Research, 51(S1):1580-1587.

Engle, R.W., Tuholski, S.W., Laughlin, J.E. \& Conway, A.R.A. 1999. Working memory, short-term memory and general fluid intelligence: a latent-variable approach. Journal of Experimental Psychology, General, 128(3):309-331.

Ericsson, K.A. \& Kintsch, W. 1995. Long-term working memory. Psychological Review, 102(2):211-245.

Garcia, L., Nussbaum, M. \& Preiss, D.D. 2011. Is the use of information and communication technology related to performance in working memory tasks? Evidence from seventh-grade students. Computers and Education, 57(3):2076-2086.

Gathercole, S.E. \& Alloway, T.P. 2004. Understanding working memory: a classroom guide. London: Harcourt Assessment.

Gathercole, S.E. \& Alloway, T.P. 2008. Working memory and learning: a practical guide for teachers. London: Sage.

Gathercole, S.E. \& Pickering, S.J. 2000. Working memory deficits in children with low achievements in the national curriculum at 7 years of age. British Journal of Educational Psychology, 70(2):177-194.

Gathercole, S.E. \& Pickering, S.J. 2003. Working memory deficits in children with special educational needs. British Journal of Special Education, 28(2):89-97.

Gathercole, S.E. 1998. The development of memory. Journal of Child Psychology and Psychiatry and Allied Disciplines, 39(1):3-27.

Gathercole, S.E. 2006. Non-word repetition and word learning: The nature of the relationship. Applied Psycholinguistics, 27(4):513-43.

Gathercole, S.E., Lamont, E. \& Alloway, T.P. 2006. Working memory in the classroom. In: S.J. Pickering (Ed). Working memory and education. San Diego, CA: Academic. 219-240.

Gathercole, S.E., Pickering, S.J., Ambridge, B. \& Wearing, H. 2004. The structure of working memory from 4 to 15 years of age. Developmental Psychology, 40(2):177-190.

Henry, L.A., Messer, D.J. \& Nash, G. 2014. Testing for near and far transfer effects with a short, face-to-face adaptive working memory training intervention in typical children. Infant and Child Development, 23(1):84-103. 
Heyes, S.B., Zokaei, N., Van der Staaij, I., Bays, P.M. \& Husain, M. 2012. Development of visual working memory precision in childhood. Developmental Science, 15(4):528-539.

Holmes, J. \& Gathercole, S. 2014. Taking working memory training from the laboratory into the schools. Educational Psychology: An International Journal of Experimental Educational Psychology, 34(4):440-450.

Holmes, J., Adams, J.W. \& Hamilton, C.J. 2008. The relationship between visuospatial sketchpad capacity and children's mathematical skills. European Journal of Cognitive Psychology, 20(2):272-289.

Holmes, J., Gathercole, S.E. \& Dunning, K. 2009. Adaptive training leads to sustained enhancement of poor working memory in children. Developmental Science, 12:F1-F7.

Holmes, J., Gathercole, S.E., Place, M., Dunning, K., Hilyon, K. \& Elliott, K. 2010. Working memory deficits can be overcome: impacts of training and medication on working memory in children with ADHD. Applied Cognitive Psychology, 12:9-15.

Hornung, C., Brunner, M., Reuter, R.A.P \& Martin, R. 2011. Children's working memory: its structure and relationship to fluid intelligence. Intelligence, 39(4):210-221.

Jaeggi, S.M., Buschkuehl, M., Jonides, J. \& Perrig, W.J. 2008. Improving fluid intelligence with training on working memory. Proceedings of the National Academy of Science USA, 105(19):6829-6833.

Jonides, J., Lacey, S.C. \& Nee, D.E. 2005. Process of working memory in mind and brain. Current Directions in Psychological Science, 14(1):2-5.

Kane, M.J. \& Engle, R.W. 2003. Working memory capacity and the control of attention: the contributions of goal neglect, response competition, and task set to Stroop interference. Journal of Experimental Psychology, General, 133:189-217.

Kane, M.J., Brown, L.H., McVay, J.C., Silvia, P.J., Myin-Germeys, I. \& Kwapil, T.R. 2007. For whom the mind wanders, and when: an experience-sampling study of working memory and executive control in daily life. Psychological Science, 18:614-621.

Kerns, K.A., Eso, K. \& Thomson, J. 1999. Investigation of a direct intervention for improving attention in young children with ADHD. Developmental Psychology, 16(2):273-295.

Klingberg, T. 2010. Training and plasticity of working memory. Trends in Cognitive Sciences, 14(7):317-324.

Klingberg, T., Fernell, E., Olesen, P.J., Johnson, M., Gustaffson, P., Dahlstrom, K., Gillberg, C.G., Forssberg, H. \& Westerberg, H. 2005. Computerised training of working memory in children with ADHD - a randomized, controlled trial. Journal of the American Academy of Child and Adolescent Psychiatry, 44(2):177-186.

Klingberg, T., Forssberg, H. \& Westerberg, H. 2002. Training of working memory in children with ADHD. Journal of Clinical Experimental Neuropsychology, 24(6):781-791.

Kronenberger, W.G., Pisoni, D.B., Henning, S.C., Colson, B.G. \& Hazzard, L.M. 2011. Working memory training for children with cochlear implants: A pilot study. Journal of Speech, Language and Hearing Research, 54(4):1182-1196. 
Kyndt, E.C., Cascallar, E. \& Dochy, F. 2012. Individual differences in working memory capacity and attention, and their relationship with students' approaches to learning. Higher Education: The International Journal of Higher Education and Educational Planning, 64(3):285-297.

Little, D.R., Lewandowsky, S. \& Craig, S. 2014. Working memory capacity: the more difficult the item, the more more is better. Frontiers in Psychology, 5:1-13.

Logie, R.H. 1995. Visuospatial Working Memory. Sussex: Lawrence Erlbaum Associates.

Masoura, E.V. \& Gathercole, S.E. 2005. Contrasting contributions of phonological short-term memory and long-term knowledge to vocabulary learning in a foreign language. Memory, 13(3/4):422-429.

Melby-Lervag, M. \& Hulme, C. 2013. Is working memory training effective? A metaanalytic review. Developmental Psychology, 49:270-291.

Minear, M. \& Shah, P. 2006. Sources of working memory deficits in children and possibilities for remediation. In: S.J. Pickering (Ed). Working memory and education. London: Elsevier. 274-307.

Miyake, A. \& Shah, P. 1999. Models of working memory: Mechanisms of active maintenance and executive control. New York: Cambridge University Press.

Morrison, A.B. \& Chein, J.M. 2012. The controversy over Cogmed. Journal of Applied Research in Memory and Cognition, 1(3):208-210.

Oberauer, K. 2005. Control of the contents of working memory - A comparison of two paradigms and two age groups. Journal of Experimental psychology: Learning, Memory and Cognition, 31(4):714-728

Olesen, P.J., Westerberg, H. \& Klingberg, T. 2004. Increased prefrontal and parietal brain activity after training of working memory. Nature Neuroscience, 7(1):75-79.

Palmer, S. 2000. Working memory: A developmental study of phonological recoding. Memory, 8(3):179-193.

Pickering, S.J. \& Gathercole S.E. 2001. Working memory test battery for children manual. London: The Psychological Corporation.

Pickering, S.J. 2001. The development of visuo-spatial working memory. Memory, 9(4):423-432.

Pickering, S.J. 2006. Working memory and education. San Diego, CA: Academic Press (Elsevier).

Rajendran, G. 2009. Working memory in children with developmental disorders. Journal of Learning Disabilities, 42(4):372-382.

Rinderman, H., Flores-Mendoza, C. \& Mansur-Alves, M. 2010. Reciprocal effects between fluid and crystallized intelligence and their dependence on parents' socioeconomic status and education. Learning and Individual Differences, 20(5):544-548.

Sabol, T.J. \& Pianta, R.C. 2012. Patterns of school readiness forecast achievement and socio-emotional development at the end of elementary school. Child Development, 83(1):282-299. 
Schmidt, R.A. \& Bjork, R.A. 1992. New conceptualisations of practice: Common principles in three paradigms suggest new concepts for training. Psychological Science, 3(4):207-217.

Seigneuric, A., Ehrlich, M.F., Oakhill, J.V. \& Yuill, N.M. 2000. Working memory resources and children's reading comprehension. Reading and Writing, 13(1/2):81-103.

Shipstead, Z., Hicks, K.L. \& Engle, R. 2012. Cogmed working memory training: Does the evidence support the claims? Journal of Applied Research in Memory and Cognition, $1(3): 185-193$.

Simmering, V.R. \& Perone, S. 2013. Working memory capacity as a dynamic process. Frontiers in Psychology, 3:1-26.

Simmering, V.R. 2012. The development of visual working memory capacity during early childhood. Journal of Experimental Child Psychology, 111:695-707.

St Clair Thompson, H., Stevens, R., Hunt, A. \& Bolder, E. 2010. Improving children's working memory and classroom performance. Educational Psychology, 30(2):203-219.

Stevenson, C.E., Bergwerff, C.E., Heisera, W.J. \& Resinga, W.C.M. 2014. Working memory and dynamic measures of analogical reasoning as predictors of children's math and reading achievement. Infant and Child Development, 23(1):51-66.

Thorell, L.B., Lindqvist, S., Bergman, S., Bohlin, G. \& Klingberg, T. 2009. Training and transfer effects of executive functions in preschool children. Developmental Science, 12(1):106-113.

Trbovich, P.L. \& LeFevre, J. 2003. Phonological and visuo-spatial working memory in mental addition. Memory and Cognition, 31(5):738-745.

Wechsler, D. 2009. Wechsler Memory Scale-Fourth Edition (WMS-IV) technical and interpretive manual. San Antonio, TX: Pearson.

Wilhelm, O. \& Engle, R.W. (Eds). 2005. Handbook of understanding and measuring intelligence. London: Sage. 